\title{
How easy it can be to incur unintentional duplication. A case of "self-plagiarism"
}

La facilidad con la cual se incurre en una duplicación involuntaria.

\section{A propósito de un caso de "Autoplagio"}

\section{Lucas-López Juan Raúl*iD) Balcázar-Nakamatsu Stephanie ${ }^{(D)}$, Tirado Oliver ${ }^{(D)}$, Rodríguez Gutiérrez Alejandro}

\begin{tabular}{l}
\multicolumn{1}{c}{ Data of the Article } \\
\hline National University of San Marcos. \\
Faculty of Veterinary Medicine. \\
Av. Circunvalación 2800. \\
San Borja 15021, Lima, Peru. \\
* Contact address: \\
National University of San Marcos. \\
Faculty of Veterinary Medicine. \\
Av. Circunvalación 2800. \\
San Borja 15021, Lima, Peru. \\
Juan Raúl Lucas-López \\
E-mail address : jrlucas.pe@gmail.com \\
\hline \\
Keywords: \\
Autoplagio, \\
publicación duplicada, \\
plagio.
\end{tabular}

J. Selva Andina Anim. Sci. 2021; 8(1):53-55.

\section{Record from the article}

Recibido noviembre, 2020

Devuelto enero, 2021.

Aceptado febrero, 2021

Disponible en línea, abril, 2021.

ID of article: 081/JSAAS/2020

Edited by: Selva Andina Research Society
Mr. Editor.

Using the definitions of the International Committee of Medical Journal Editors- "a duplicate publication is the publication of a manuscript that substantially overlaps with one already published without clear, visible reference to the previous publication". We wrote this letter to make public and transparent a case of unintentional duplicate publication, described below: Looking for a suitable journal in which to publish the article entitled "The pH of guinea pig (Cavia porcellus) meat from the welfare-deficient slaughtering in the Peruvian central Andes", it was identified potential veterinary journals or scope-similar journals (e.g., agricultural sciences), to expand our universe of eligible journals for this type of studies. Two proposals were selected, and although the journal "FAVE-Ciencias Agrarias" (ISSN: 2346-9129) was initially considered as the first option, since it was indexed in Scopus, it was finally decided to publish in the "Revista Veterinaria" (ISSN: 1669-6840), also indexed but more related to the proposed topic. Therefore, the format of the article originally entitled "The $\mathrm{pH}$ of meat of guinea pig (Cavia porcellus) for human consumption in the Peruvian central Andes" was submitted following the guidelines of the "Revista Veterinaria". Before making this decision, the cover letters were prepared for each journal in which the publication copyrights were transferred to each of them. Both documents were enclosed in an e-mail that was also provisionally addressed to the e-mail accounts of the two editors of the journals and awaiting an internal agreement between the authors to decide to which of the two e-mail addresses and which of the two cover letters would remain when sending the final version of the article.

From the authors' perspective, a crucial moment, for being the origin of this unintentional and negligent error, was on May 10, 2017, when we submitted the article via e-mail to the editor of the "Revista Veterinaria" but with the cover letter and, consequently, the copyright transferred to the journal "FAVE-Ciencias Agrarias". Even worse, all these documents were inadvertently and mistakenly sent to the e-mail addresses of both journal editors.

With an automatic reply mail from the "Revista Veterinaria", we were informed of the reception of the article. Weeks later, on June 23, we were contacted by the Journal "FAVECiencias Veterinarias" (ISSN: 2362-5589); we had not had any contact with this journal, nor had we considered it until that moment. In fact, no cover letter had been written for this journal, 
nor was its editor among the recipients of the e-mail in which the article was sent, nor was the manuscript in the format required by this journal. This "FAVE-Ciencias Veterinarias" journal sent corrections and comments for our article. After inquiring about the origin of this evaluation among our communications and after asking the editor of "FAVE-Ciencias Veterinarias", he informed us that the editor of "FAVE Ciencias Agrarias" sent our article to "FAVE-Ciencias Veterinarias" without noticing us, considering that it was a more pertinent journal for the diffusion of our work. We immediately notified the "Revista Veterinaria" of the mistakes committed, besides asking about the situation of our article, under the very probable suspicion that it has been withdrawn from the evaluation process due to such a terrible confusion. At the same time, we also informed the journal "FAVE-Ciencias Veterinarias" about the simultaneous submission.

On September 12, in the absence of a response from the "Revista Veterinaria", and assuming as feasible the possibility that our article had been discarded for review, we decided to continue with the publication process with the "FAVE-Ciencias Veterinarias" journal, which as mentioned above had already reviewed and submitted comments that improved our initial submission. On September 22, the article was published online entitled "The pH of guinea pig (Cavia porcellus) meat from the welfare-deficient slaughtering in the Peruvian central Andes", Volume 16, Number 2, 2017. Months later we also received a google scholar alert about the publication of the article submitted on May 10, 2017, to the "Revista Veterinaria", which was accepted for publication on July 31,2017 , as stated in a footnote to the article, but published in volume 29, number 1, 2018. This article, "The $\mathrm{pH}$ of meat of guinea pig (Cavia porcellus) for human consumption in the Peruvian central Andes", was accepted without any change from its original version, we were not notified of its acceptance nor did we receive any galley proof. This procedure was critical and, from our point of view, contributes to the possibility of unintentional duplication.

According to the Committee on Publication Ethics ${ }^{2}$, the present problem constitutes grounds for retraction of the publication, the recommendation states that the journal that first published the article may report the case of duplication, but should not retract the article, instead, journals that subsequently publish the article should retract it and state the reasons for the retraction. Although chronologically the "Revista Veterinaria" was the first to accept the manuscript (31/07/2017 vs. 22/09/2017), it was "Fave-Ciencias Veterinarias" who published it, on line, in the first instance (2017 vs. 2018), and who managed more coherently this process according to the usual ethical considerations of the publication procedure. Paradoxically, neither of these two journals has a cover letter in which the copyright of publication is transferred. To date, and after several attempts to publish this letter in one of the journals involved, we decided to appeal to "the Journal of the Selva Andina Animal Science".

This case is now part of the unfortunate number of examples in which misconduct such as duplicate publication occur. This letter presents a case from the point of view of the authors, who acted negligently, but reject the deliberate double submission, and consider that the lack of communication from one of the journals involved has been a determining factor in incurring 
in this fault. Therefore, this letter is a reminder to institutions and their researchers to establish mechanisms to avoid incurring in such misconduct, such as the promotion of responsible research behavior, for example. It is also a call to authors, editors, reviewers, and readers to be alert to cases of duplicate publication, whether intentional or not, which over time would strengthen transparency and contribute to increasingly mitigate this type of problem. We consider that the fundamental tool to achieve this objective is to facilitate the communication between editors and authors throughout the process, and between editors and readers after publication.

\section{Conflicts of interest}

The authors declare that they have no conflict of interest.

\section{Acknowledgments}

We are grateful to the Editor in Chief of the Journal of the Selva Andina Animal Science for accepting this letter for publication.

\section{Cited Literature}

1. Recommendations for the conduct, reporting, editing, and publication of scholarly work in medical journals [Internet]. International Committee of Medical Journal Editors. 2018 [citado 5 de octubre de 2020]. Recuperado a partir de: http://www.icmje.org/ recommendations/archives/2018 dec_urm.pdf
2. Simultaneous submission without aiming at duplicate publication [Internet]. Comité de Ética en Publicación. 2020 [citado 5 de octubre de 2020]. Recuperado a partir de: https://publicationethics. org/case/simultaneous-submission-without-aimingduplicate-publication

\section{Editor's Note:}

Journal of the Selva Andina Animal Science (JSAAS) remains neutral with respect to jurisdictional claims published on maps and institutional affiliations. 